Trivent Publishing

(C) The Authors, 2016

Available online at http://trivent-publishing.eu/

Engineering and Industry Series

Volume Power Systems, Energy Markets and Renewable Energy Sources in

South-Eastern Europe

\title{
The Metering Interface between the SCADA and SRAAMD Systems
}

\author{
Mirela Đurđević, ${ }^{1}$ Vladimir Grujić ${ }^{2}$ \\ ${ }^{1}$ Operational Technology Department, Serbian Transmission System, and \\ Market Operator, Serbia, mirela.djurdjevic@ems.rs \\ ${ }^{2}$ Market Division, Serbian Transmission System, and Market Operator, \\ Serbia, vladimir.grujic@ems.rs
}

\begin{abstract}
The SCADA System (Supervisory Control and Data Acquisition) is a system which provides real-time monitoring and control capabilities for distributed industrial systems such as electric power transmission. The SRAAMD System is the System for the Remote Acquisition and Accounting of Metering Data.

The Metering Interface is the interface between the SCADA NCC system and the SRAAMD system. SCADA and SRAAMD are systems for data acquisition. Exchanged data between these two systems is considerable for the entire TSMO. This interface provides a better quality and redundancy for collected data.
\end{abstract}

\section{Keywords}

SCADA-EMS; SRAAMD; HIS; metering, system; data; exchange; interface 


\section{Introduction}

This paper will describe the interface between the SCADA/EMS and SRAAMD systems in the National Dispatching Centre of the Serbian TSMO. Data exchange is realized through a two-way communication. The work of the transmission system of Serbia is improved with this link; i.e. the system operates with better reliability.

The exchange of data is done in the XML format (Extensible Markup Language). This provides fast and confidential data exchange. Remote data acquisition according to standard protocols is enabled with high and precise electrical energy metering devices, with an accuracy class of 0.2.

\section{The SCADA/EMS System}

SCADA is a system used for data acquisition and the control of the transmission system by dispatchers in the National Control Centre (NCC). The EMS is the Energy Management System - the system of grid application, used for a working analysis of the transmission system. [4]

The SCADA/EMS system is shown in Fig.1. [1]

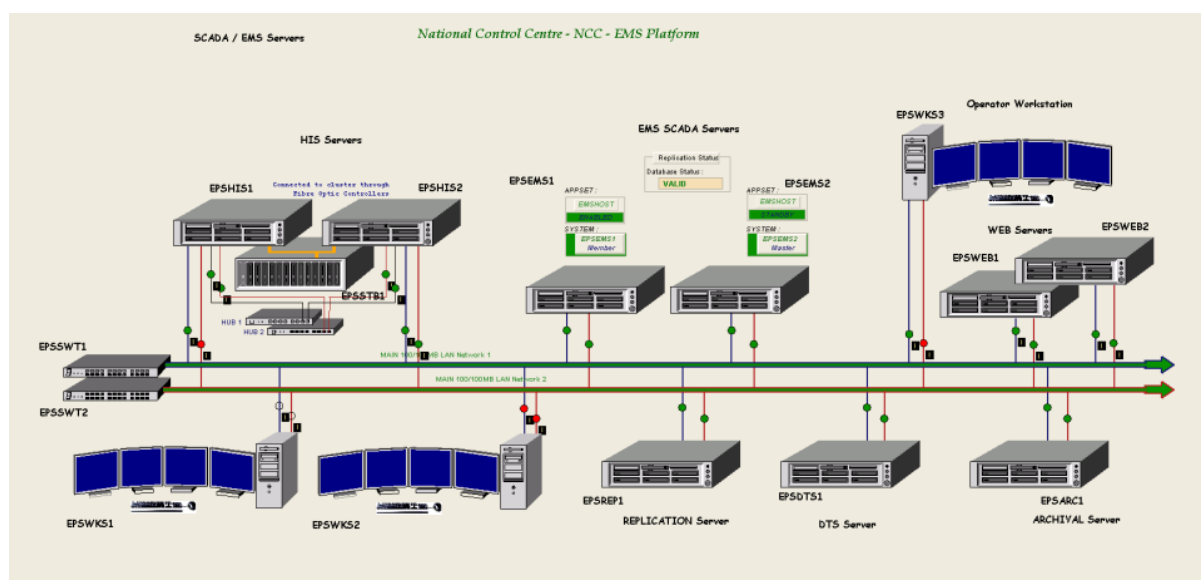

Fig. 1. NCC SCADA/EMS Platform

This system, called EMS or SCADA/EMS, enables, aside from SCADA functions, a set of EMS functions for the electrical network management and the management of work order on the network.

The system will feature the following minimal characteristics:

- Scalable architecture, wherein all functions, both the SCADA system and Transmission Network 
Management system (EMS), are integrated in a modular way and can be integrated in a single server for TCO (Total Cost Ownership) optimization.

- Reliability: redundancy of critical SCADA and Transmission network Management (EMS) functions in order to warranty a high level availability of up to $99.99 \%$ ).

The SCADA System supports the following:

- Main Site with redundancy for all critical functions.

- Must support a minimum of two multi-standby configurations and a parallel site configuration that would be possible for future needs.

The system supports the following environments:

- Production environment.

- Development and maintenance/dispatcher training environment.

- External access environment.

SCADA/EMS modules are shown in Fig.2.

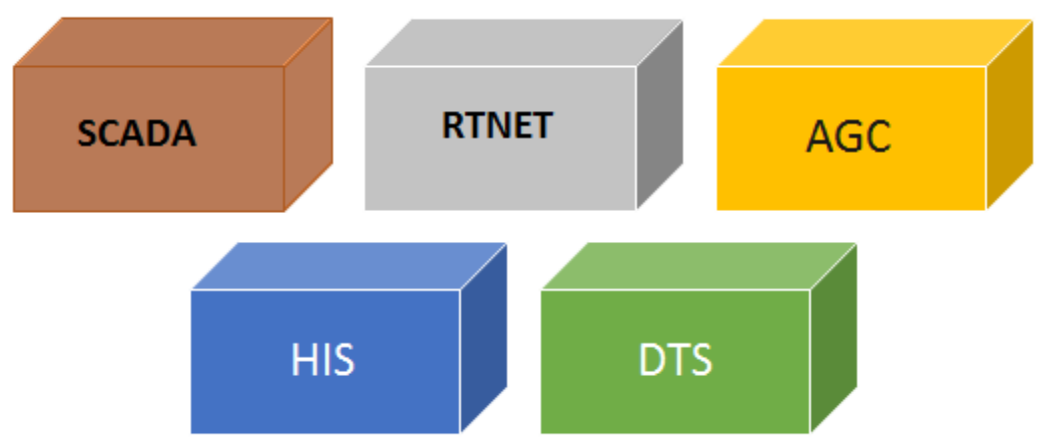

Fig. 2. NCC SCADA/EMS Moduls

The main parts of this concept are:

- SCADA basic module - real-time data functionality.

- RTNET module - power applications such as state estimator, contingency analyses, etc.

- AGC - Automatic Generation Control module.

- HIS - Historical Information System.

- DTS - Dispatcher Training Simulator. 


\section{SRAAMD System}

SRAAMD is a system for remote data collection from electrical energy metering devices and using this data for market calculations.

There are more than 900 high quality electric meters on the transmission grid of TSMO Serbia, which are always available. Data is collected at 15-minute intervals.

Accessibility of data enables three ways of communication:

- Public phone link.

- Mobile link.

- Optical link.

With the development of the optical link and OPGW (Optical Power Ground Wire), cable accounts are available on-line. With this technical opportunity, speed and data transfer is of high quality. The SRAAMD system and OPGW technology was a first step towards the successful introduction of a modern billing and settlement practice in the free energy market in Serbia [5].

Because the SRAAMD system is very important, redundant communication has become a standard in this system.

The SRAAMD user interface is shown in Fig.3.

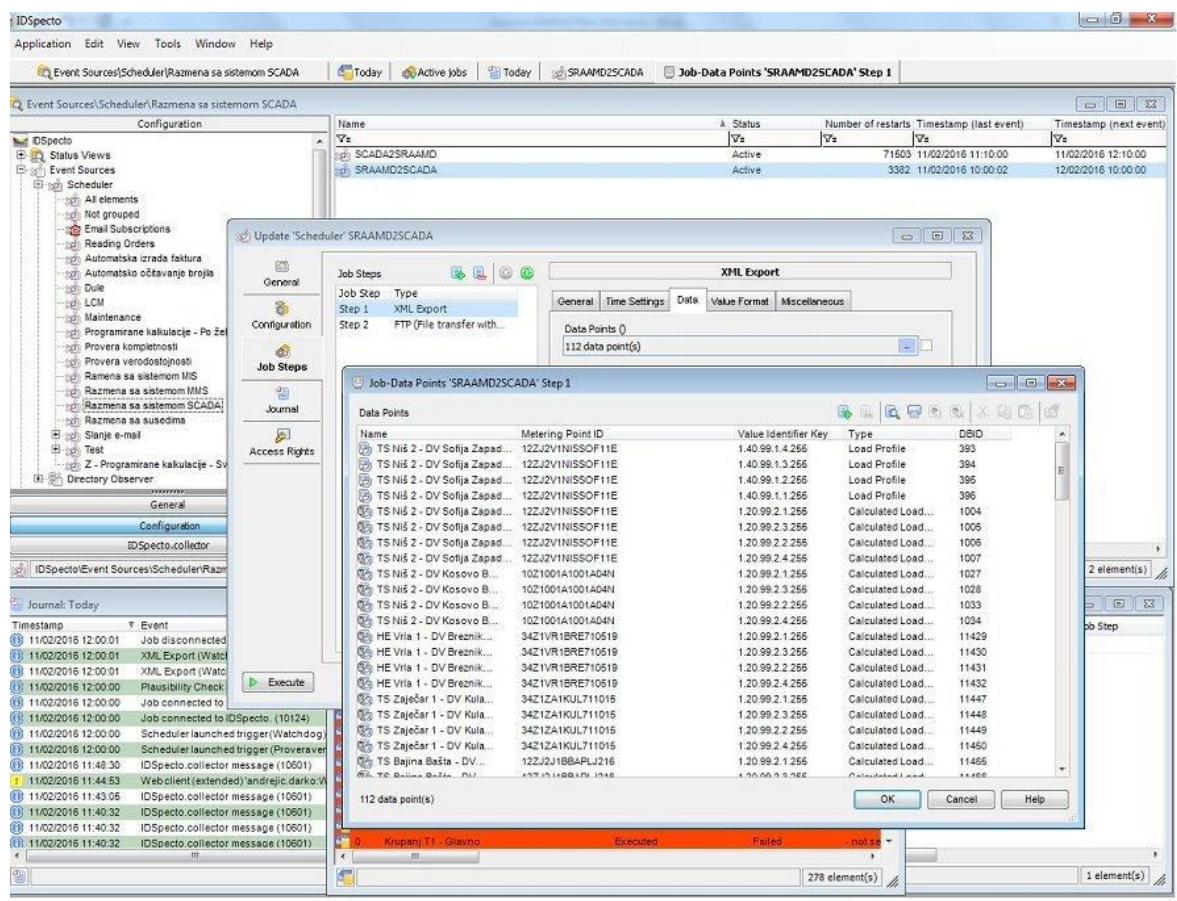

Fig. 3. SRAAMD User Interface 


\section{Metering Interface}

The Metering Interface is the interface between the NCC SCADA system and the System for Remote Acquisition and Account of Metering Data - SRAAMD. The NCC SCADA/EMS will be connected to the following systems:

- The Serbian Market Operator.

- The Operational Planning System (OPS).

- The Metering System, SRAAMD.

- Users from other departments;

- The Transmission Companies.

As the future SRAAMD will be likely based on an Oracle database, we use our standard HIS servers and Oracle database to assume data exchange with SRAAMD. Any real-time database information can be sampled to the Oracle HIS database if needed. A dynamic link is established easily between the tables of the HIS database and SRAAMD database using Oracle's standard utilities.

The Application Programming Interfaces (APIs) for each of the applications and the following practices and approaches are the best warranties for our system's openness:

- Extensive use of standards achieved by a corporate commitment to compliance with all standards recognized on the SCADA/EMS market. This means that the integration of any (standard-complied) third-party software or EMS-developed software will be easy and smooth.

- CIM/XML for Database Import/Export.

- Data link that allows the dynamic export of any real-time data to Microsoft PC applications (Excel, Access, etc.).

Exclusive use of Commercially Off the Shelf (COTS) hardware equipment is available from multiple vendors, going from servers, workstations, LAN/WAN to RTU communication cards.

The metering interface architecture is shown in Figure 4. 


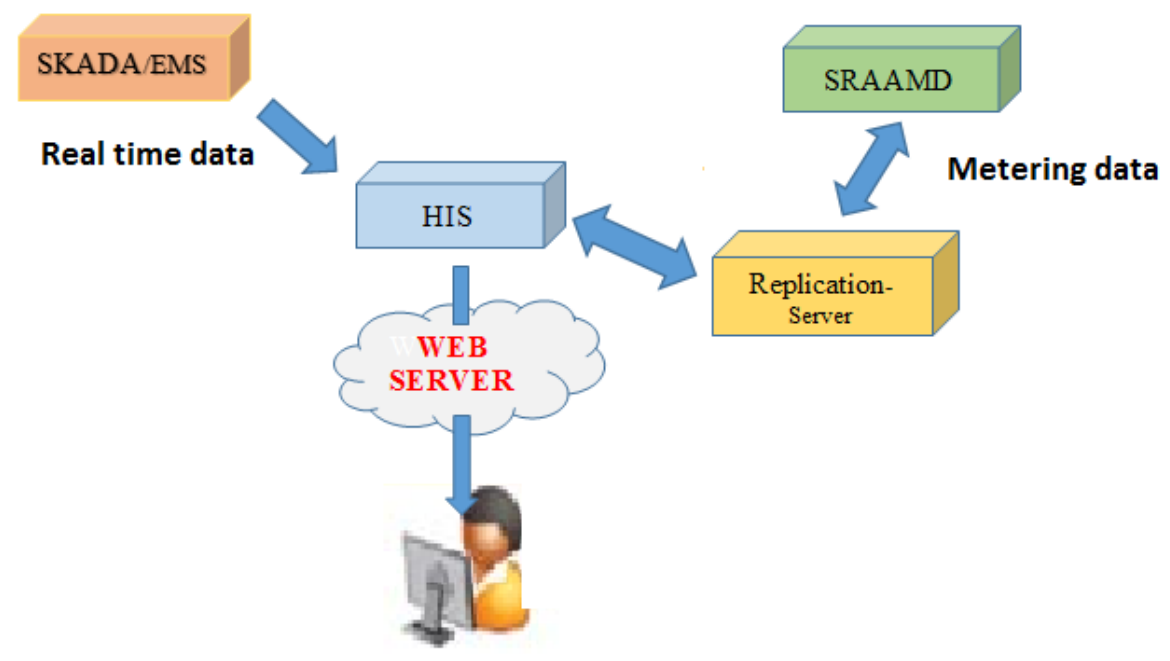

Fig. 4. Metering Interface Architecture

From SCADA to SRAAMD, the following data is exchanged:

- Hourly active/reactive energy on interconnection points from remote processors (e.g. RTUs).

- Hourly active/reactive energy on generation/transmission points from remote processors.

- Hourly active/reactive energy on transmission/distribution points from remote processors.

- Hourly active/reactive energy on transmission/large consumers points from remote

- processors.

- Changes in grid topology - hourly states of switching devices.

From SCADA to SRAAMD, the following data is exchanged:

- 15' and 60' active/reactive energy on interconnection points from meters.

- 15' and 60' active/reactive energy on generation/transmission point from meters.

- $15^{\prime}$ and $60^{\prime}$ active/reactive energy on transmission/distribution points from meters.

- $15^{\prime}$ and $60^{\prime}$ active/reactive energy on transmission/large consumers points from meters.

As energy metering is not used in real time application but mainly for archival purposes, the interface is implemented between the HIS Oracle and SRAAMD database. 
Real time data needed for metering will be stored in archive Oracle database. There are two ways to select the analogues and points that will be transferred from SCADA to HIS:

- Composite key pattern.

- Custom selection field under the analogue or point record.

Separate tables are created for each recording definition. UTC time is used in all transfers. All data exchanges are realized using XML files.

Each system is responsible for generating XML files from the Oracle database, connecting to other system, and delivering XML files, as well as detecting newly received files and integrating them into the database.

Data exchange between the SCADA and SRAAMD systems is realized via the Replication server. The Replication server has two tasks, Metering Export and Metering Import, scheduled at system start-up. Task Metering Export must run every hour, as its role to export regularly the counter values from HIS servers to the SRAAMD system through the Replication server. Otherwise, the Metering Import task must run once a day.

Figure 5 shows the SCADA - SRAAMD data flow.

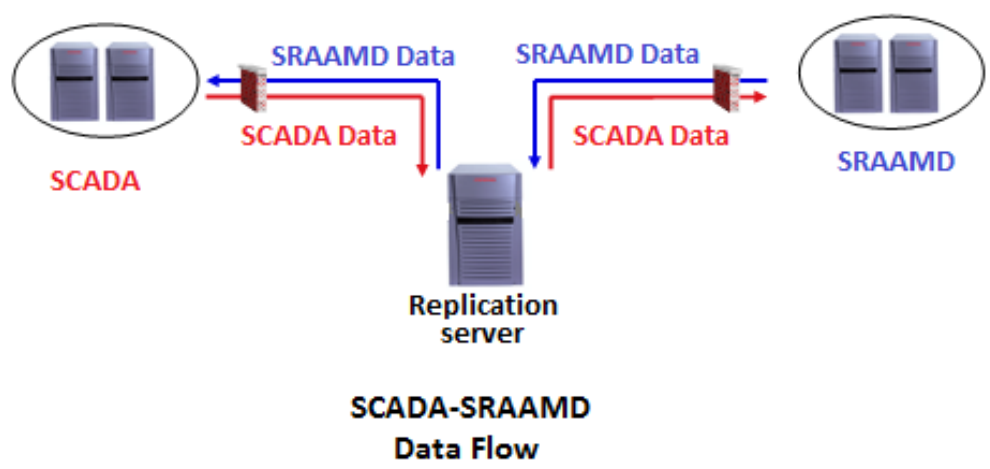

Fig. 5. SCADA - SRAAMD Data Flow

\section{Conclusion}

The conditions of planning and implementing the SCADA/EMS system change over time. The SCADA/EMS system should be easily adaptable for changes during exploitation. Requirements for more data are received from the Serbian power system and neighbouring power systems.

The tendency for deregulation in the electricity market presents requirements as well.

During the exploitation of both systems, SCADA and SRAAMD, the metering interface proved as a very effective concept. Considering the importance of the SCADA and SRAAMD systems, the proposal is to establish a 
redundant link and interface between SRAAMD and the NCC SCADA backup system as well. The advantage of this solution is the fact that the NCC SCADA systems are made by different vendors. In this way, the dispatching of the transmission system will be done with a very high redundancy.

\section{References}

AREVA Technical Offer, vol.II, Chapter 8 PSA: Network subsystem, 2004. EPS-P1-IS-006 Metering Interface Project Note-Rev 2.1, 2005.

Görlitz Schweiz AG: Application Software, Zug, Switzerland, 2005.

Djurdjević, M., and M. Novakovic, Z. Milinic, S. Dzonlez. "SCADA/EMS sistem u NDC EMS: sagledavanje novih potreba i mogućnosti tokom eksploatacije sistema" (SCADA/EMS System in NDC Serbian TSMO: consideration of new needs and opportunities during the exploitation of the system), 31 . Symposium CIGRE, Zlatibor, Serbia, pp 3. and 4. 05. 2013. (In Serbian) Grujić, V. "Razmena podataka između SRAAMD i SCADA/EMS sistema" (Exchanging data between SRAAMD and SCADA/EMS systems), 32. Symposium ENERGETIKA, Zlatibor, Serbia, 22.- 25.03.2016. (In Serbian) 